\title{
Release of cytokines by stimulated peripheral blood mononuclear cells in chronic periodontitis
}

\author{
Thais Oliveira Gonçalves ${ }^{a}$, Dirceu Cost $a^{b}$, Claudia Ida Brodskyn ${ }^{b}$, Poliana Mendes Duarte ${ }^{c}$, \\ João Batista César Neto ${ }^{d}$, Getulio Nogueira-Filho ${ }^{e, *}$ \\ ${ }^{a}$ Department of Prosthodontics and Periodontics, Faculty of Dentistry of Piracicaba, UNICAMP, Piracicaba, São Paulo, Brazil \\ ${ }^{\mathrm{b}}$ Laboratory of Immunology and Parasitology (LIP), FIOCRUZ, Salvador, Bahia, Brazil \\ ${ }^{\mathrm{c}}$ Department of Periodontics, Dental Research Division, Guarulhos University, Guarulhos, São Paulo, Brazil \\ ${ }^{\mathrm{d}}$ Department of Periodontology, University of São Paulo, School of Dentistry (USP), São Paulo, São Paulo, Brazil \\ ${ }^{\mathrm{e}}$ Department of Dental Diagnostic and Surgical Sciences, Division of Periodontics, Faculty of Dentistry, University of Manitoba, D343-790 \\ Bannatyne Ave, Winnipeg, MB, Canada R3E OW2
}

\section{A R T I C L E I N F O}

Article history:

Accepted 9 August 2010

Keywords:

Periodontitis

Cytokines

ELISA

Mononuclear cell

PBMC

\begin{abstract}
A B S T R A C T
Objective: The emergence of periodontal medicine increased interest in defining the behaviour of peripheral blood cells in periodontitis subjects in comparison with healthy group. The aim of this study was to evaluate the levels of interleukin (IL)-8, tumour necrosis factor$\alpha$ (TNF- $\alpha$ ), IL- 6 and IL-10 released by Escherichia coli lipopolysaccharide (LPS)-stimulated peripheral blood mononuclear cells (PBMC) obtained from the peripheral blood of chronic periodontitis subjects.

Design: PBMC samples were isolated from 19 systemically healthy donors, divided into generalized chronic periodontitis $(n=10)$ and healthy $(n=9)$ subjects. Cells were incubated for 24-48 h in $500 \mu \mathrm{L}$ wells containing RPMI 1640 and stimulated with $1.0 \mathrm{ng} / \mathrm{mL}$ of E. coli LPS. Supernatants were used to quantify the amounts of IL-8, TNF- $\alpha$, IL- 6 and IL-10 released using enzyme-linked immunosorbent assay (ELISA).

Results: PBMC cells from periodontitis subjects released higher levels of TNF- $\alpha$ and IL- 6 than those from healthy subjects $(P<0.05)$. Conversely, the supernatants of the stimulated PBMC cells obtained from healthy subjects presented higher amounts of IL- 8 than those from periodontitis $(P<0.05)$. No differences were observed in the levels of IL-10 $(P>0.05)$ between groups.

Conclusion: In conclusion, the results of the present study showed that E. coli LPS-stimulated PBMC from subjects with periodontitis present a different pattern of cytokine release when compared to PBMC from healthy subjects. This phenomenon could have implications locally, in periodontitis, as well as in systemic diseases.
\end{abstract}

(C) 2010 Elsevier Ltd. All rights reserved.

\section{Introduction}

Periodontal diseases are well recognized as a result of the interaction between host immune response and pathogenic bacteria species of the dental biofilm. ${ }^{1}$ During the last few decades, evidence has linked periodontal infections with an increased risk of systemic complications, including rheumatoid arthritis, respiratory and cardiovascular diseases, diabetes mellitus and preterm low birth weight. ${ }^{2-4}$ Although the precise mechanisms that explain the relationship between

\footnotetext{
* Corresponding author. Tel.: +1 204789 3597; fax: +1 2042723077.

E-mail address: nogueira@cc.umanitoba.ca (G. Nogueira-Filho). 0003-9969/\$ - see front matter (C) 2010 Elsevier Ltd. All rights reserved. doi:10.1016/j.archoralbio.2010.08.002
} 
systemic and periodontal diseases have not been completely elucidated, low-grade chronic inflammatory burden has been suggested as a plausible biological process linking periodontitis and systemic disorders. The periodontal diseases seem to act as a source of pathogenic species, virulence factors and inflammatory mediators that spread systemically, creating and sustaining a chronic systemic inflammatory burden. ${ }^{5-7}$

Inflammation is initiated and maintained by the emergence of a network of chemokines (e.g. IL-8), pro- (e.g. tumour necrosis factor (TNF)- $\alpha$, interleukin (IL)-1 $\beta$, IL-12 and IL- 6 ) and anti-inflammatory mediators (e.g. IL-10, IL-1 antagonist and IL-4) that play distinct or shared biological activities. ${ }^{8}$ The chemokine, IL-8, mainly attracts and activates neutrophils, and is considered important mediators for granulocyte accumulation. ${ }^{9}$ TNF- $\alpha$ stimulates the production of collagenase, prostaglandin $\mathrm{E}_{2}$, chemo- and cytokines, cellular adhesion molecules and bone resorption-related factors. ${ }^{10,11} \mathrm{IL}-6$ induces the expression of C-reactive protein (CRP), an acutephase reactant responsible for the increase in the expression of cellular adhesion molecules and vascular inflammation. Based on the biological properties of these pro-inflammatory cytokines, high plasma levels of TNF- $\alpha$ and IL- 6 have been associated with an increased risk for developing cardiovascular events, morbidity and mortality. ${ }^{12,13}$ Conversely, IL-10, which is delivered by both innate and adaptive immune cells, controls and suppresses the inflammation so as to downregulate the adaptive immune reaction and minimize tissue destruction in response to microbial challenges. ${ }^{14}$ This cytokine is also able to inhibit the expression of several proinflammatory cytokines, impairing the ability of $\mathrm{T}$ cells to sustain inflammatory responses to antigenic challenges. ${ }^{14}$

Mononuclear leukocytes, consisting of lymphocytes and monocytes, are one of the main sources of inflammatory cytokines. It has been proposed that cytokine production by peripheral blood mononuclear cells (PBMCs) may reflect the activity of immuno-inflammatory diseases in specific organs and tissues. ${ }^{15-17}$ In addition, it has also been suggested that PBMC from periodontitis subjects may present a distinct profile of inflammatory mediator release in response to different bacterial challenges when compared to those of healthy subjects. ${ }^{17-21}$ An unfavourable profile of cytokine release by PBCM in periodontitis subjects could imply not only an intense periodontal tissue breakdown, but also a systemic inflammatory burden that could be associated with various systemic disorders. Therefore, the aim of this study was to evaluate the levels of interleukin-8 (IL-8), tumour necrosis factor- $\alpha$ (TNF- $\alpha$ ), interleukin-6 (IL-6) and interleukin-10 (IL-10) released by PBMC stimulated by Escherichia coli lipopolysaccharide (LPS) obtained from the peripheral blood of chronic periodontitis subjects.

\section{Materials and methods}

\subsection{Study population}

Nineteen subjects (age range: $31-57$ years) were selected from the population referred to the Periodontal Clinic of Bahian Science Foundation (EBMSP), from March 2005 until January 2006. Subjects who fulfilled the following inclusion/exclusion criteria were invited to participate in the study. All eligible subjects were, on an individual basis, informed about the nature of the proposed study, and informed consent forms were signed. The Review Ethics Board of the Faculty of Dentistry of Piracicaba has approved this protocol (\#049/2005).

Exclusion criteria were pregnancy, lactation, periodontal or/and antibiotic therapies in the previous 12 months, systemic conditions that could affect the progression of periodontitis (e.g. immunological disorders and diabetes), mononuclear blood cell dysfunctions and infectious diseases other than periodontitis. Subjects on long-term use of antiinflammatory and immunosuppressive medications that could alter leucocyte function were also excluded.

\subsection{Experimental design}

Within a month after clinical and radiographic examinations, peripheral blood samples were obtained from each of the 19 subjects that were divided into two groups according to their periodontal status: P-generalized chronic periodontitis $(n=10)$ and H-periodontal health $(n=9)$. The diagnosis of generalized chronic periodontitis was based on the clinical and radiographic criteria proposed by the 1999 World Workshop for Classification of Periodontal Diseases and Conditions. ${ }^{22}$ Periodontitis subjects were $>30$ years old, had at least 15 teeth, $>30 \%$ of the sites with probing depth (PD) and clinical attachment level (CAL) $>5 \mathrm{~mm}$ and $>60 \%$ of the sites with plaque accumulation (PL), marginal bleeding (MB) and bleeding on probing (BOP). Healthy individuals presented no history of periodontitis, $\mathrm{PD}$ and CAL measurements $<3 \mathrm{~mm},<20 \%$ of the sites with $\mathrm{PL}, \mathrm{MB}$ and BOP. Subjects from $\mathrm{P}$ and $\mathrm{H}$ groups were matched for age, gender and smoking status. The demographic and periodontal characteristics of the subjects according to the inclusion criteria are summarized in Table 1.

\subsection{Blood sampling and PBMC separation}

About 20-25 mL of peripheral blood was collected from each subject by venipuncture into heparinized tubes. The blood was

\begin{tabular}{|c|c|c|}
\hline Characteristics & Healthy & Periodontitis \\
\hline Number of patients & 9 & 10 \\
\hline Age (years; mean $\pm \mathrm{SD}$ ) & $35.22( \pm 3.31)$ & $40.30( \pm 3.41)$ \\
\hline F (female)/M (male) & F 4/M 5 & F $5 / \mathrm{M} 5$ \\
\hline Smokers & 5 & 5 \\
\hline Plaque accumulation (\%) & $<20$ & $>60$ \\
\hline Marginal bleeding (\%) & $<20$ & $>60$ \\
\hline Bleeding on probing (\%) & $<20$ & $>60$ \\
\hline Probing depth & $\begin{array}{l}100 \% \text { of the sites } \\
<3 \mathrm{~mm}\end{array}$ & $\begin{array}{l}30 \% \text { of the sites } \\
>5 \mathrm{~mm}\end{array}$ \\
\hline Clinical attachment level & $\begin{array}{l}100 \% \text { of the sites } \\
<3 \mathrm{~mm}\end{array}$ & $\begin{array}{l}30 \% \text { of the sites } \\
>5 \mathrm{~mm}\end{array}$ \\
\hline
\end{tabular}

There are no differences between groups regarding age (MannWhitney rank sum test; $P>0.05)$, gender and smoking status $\left(\chi^{2}\right.$ test; $P>0.05$ ). 
diluted 1:1 in saline solution and layered over Ficoll-Hypaque 1077 (Sigma, St. Louis, MO, USA) (density: $1.077 \mathrm{~g} / \mathrm{mL}$ ) for separation of mononuclear cells. After separation, cells were washed by three centrifugations, $10 \mathrm{~min}$ each at 453, 244 and $201(\times g)$, successively. The cells were resuspended in supplemented RPMI [RPMI 1640 R-0883 (Sigma, St. Louis, MO, USA), with HEPES Buffer 11203 (Gibco, Grand Island, NY, USA), L-glutamine (2 mM), penicillin (100 U/mL), streptomycin $(1 \%)]$ and $3.8 \%$ sodium citrate, $\mathrm{pH} 7.2(9: 1, \mathrm{v} / \mathrm{v})$ and adjusted to a concentration of $5 \times 10^{6}$ cells $/ \mathrm{mL}$ using a hemocytometer. Aliquots of each cell suspension $(500 \mu \mathrm{L})$ were then plated into chambers of 24-well culture dishes, treated with either supplemented RPMI 1640 alone or with supplemented RPMI 1640 containing $1.0 \mathrm{ng} / \mathrm{mL}$ of LPS from E. coli (L-4391, 0111:B4, Sigma, St. Louis, MO, USA) and incubated for $24-48 \mathrm{~h}$ at $37^{\circ} \mathrm{C}$ in a $5 \% \mathrm{CO}_{2}$ humidified atmosphere. PBMC viability was assessed by trypan blue exclusion of cells. The viability was $\geq 95 \%$ in all experiments, regardless of treatment condition. Six-hundred microlitres of supernatants from activated and non-activated (control) PBMC were obtained by centrifugation and stored in microtubes at $-20{ }^{\circ} \mathrm{C}$ until determination of cytokine concentration.

\subsection{Enzyme-linked immunoabsorbent (ELISA) assay}

The levels of IL-8, TNF- $\alpha$, IL- 6 and IL-10 in supernatants were determined by ELISA using commercial anti-cytokine antibody pairs (Becton Dickson, Pharmingen, San Jose, CA, USA), according to the manufacturer's protocols. Human recombinant TNF- $\alpha$, IL-6, IL-8 and IL-10 (Becton Dickson, Pharmingen, San Jose, CA, USA) were used to generate standard curves. Briefly, polystyrene high-binding 96-well microtiter plates (Nunc-Immuno Plate; Maxisorp, Nalge Nunc, Rochester, NY, USA) were coated with capture antibody for each individual cytokine. After overnight incubation at $4{ }^{\circ} \mathrm{C}$, the plates were washed (as in subsequent steps) with phosphate-buffered saline containing $0.05 \%$ Tween 20 and $0.4 \mathrm{M} \mathrm{NaCl}$, and then incubated, for $2 \mathrm{~h}$ at room temperature, with diluent buffer (phosphate-buffered saline containing 1.0\% bovine serum albumin; $100 \mu \mathrm{L}$ per well) to block non-specific binding. After washing, samples ( $100 \mu \mathrm{L}$ per well) or the serially diluted standards of each cytokine were added to the plates, which were then incubated overnight at $4{ }^{\circ} \mathrm{C}$. After washing the plates, $100 \mu \mathrm{L}$ of biotinylated antibody was added to each well and the plates were incubated for $1 \mathrm{~h}$ at room temperature. Colour was developed by the use of peroxidase-conjugated streptavidin (1:200; $100 \mu \mathrm{L}$ per well) (DAKO Corp., Carpinteria, CA, USA) for $30 \mathrm{~min}$. After washing, the chromogen [ofenilenodiamine-2HCL (Sigma, St. Louis, MO, USA)] was added and incubation continued for $15 \mathrm{~min}$. The reactions were stopped with $150 \mu \mathrm{L}$ of $1.0 \mathrm{M} \mathrm{H}_{2} \mathrm{SO}_{4}$ and the absorbances were measured at $490 \mathrm{~nm}$ by ELISA reader. Calibration curves were plotted by regression analysis and the optical density of each sample was used to estimate the concentration of each cytokine per well. The minimum detectable dose (sensitivity) for all cytokines was $15.625 \mathrm{pg} / \mathrm{mL}$. Dilution factors were 1:10 for TNF- $\alpha$ and IL-10; 1:100 for IL- 6 and 1:50 for IL-8. Samples with cytokine levels below the detection limit of assay were scored as $0 \mathrm{pg}$. The tests were performed in duplicate for each sample.

\subsection{Statistical analysis}

All tests were performed using SAS and presented with Prism 5 (GraphPad). Cytokine data were examined for normality by the Kolmogorov-Smirnov test. Since the data did not achieve normality, the comparisons of the cytokine levels between healthy and periodontitis groups were performed using
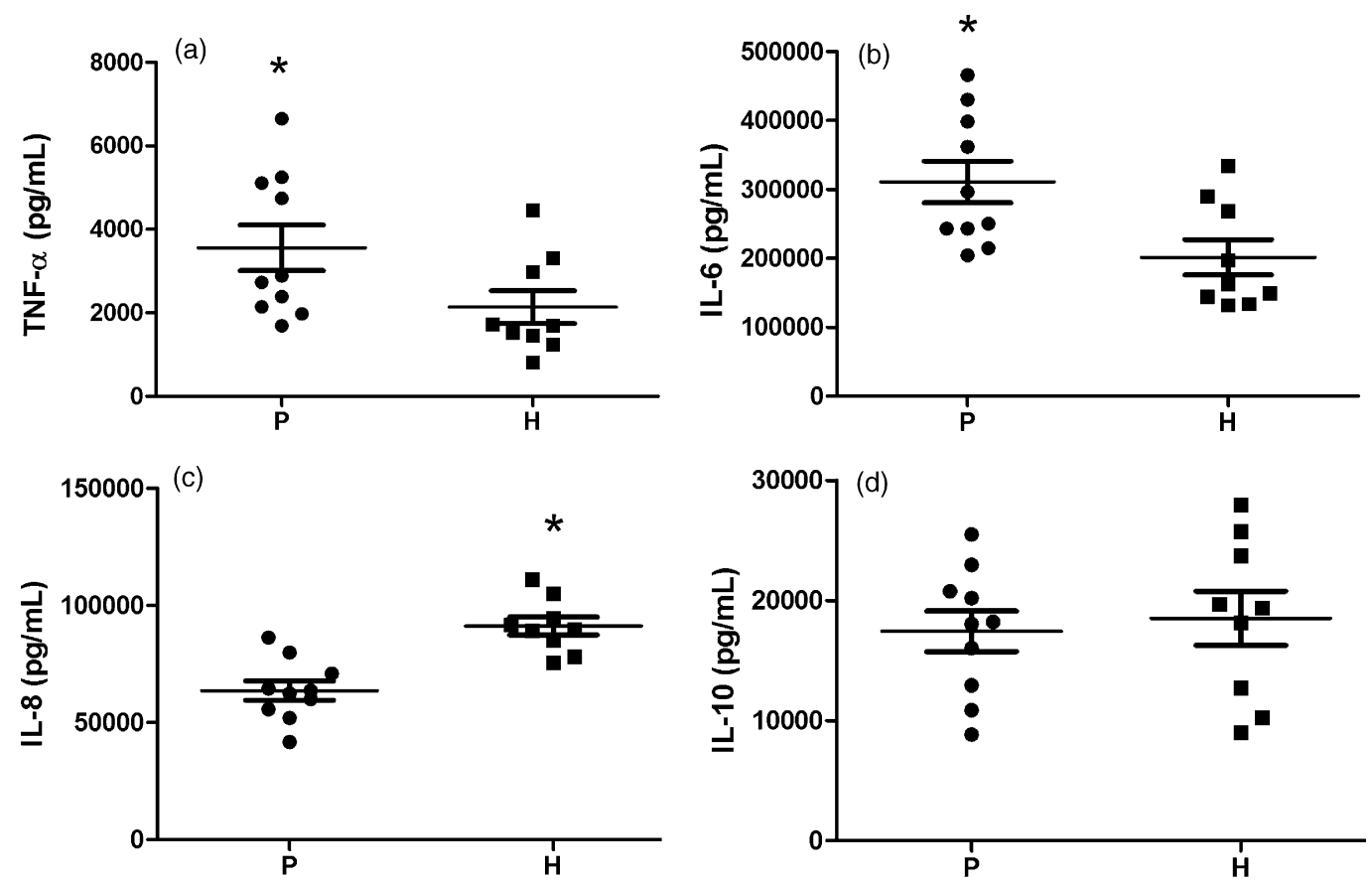

Fig. 1 - Levels of cytokines: (a) TNF- $\alpha$, (b) IL-6, (c) IL-8 and (d) IL-10 in supernatants of E. coli LPS-stimulated PBMC from periodontitis $(\mathrm{P})$ and healthy $(\mathrm{H})$ subjects. (*) Differences between groups (Mann-Whitney rank sum test; $P<0.05$ ). 
Mann-Whitney Rank Sum Test. The $\chi^{2}$ test was used to detect differences in the frequencies of gender and smoking status between groups. The significance level established for all analyses was $5 \%(P<0.05)$.

\section{Results}

The levels of TNF- $\alpha$, IL-6, IL- 8 and IL-10 were below the detection level of the assay in supernatants from nonstimulated PBMC cultures (controls).

The concentrations (pg/ml) of TNF- $\alpha$, IL- 6 , IL- 8 and IL-10 in the supernatants of the stimulated PBMC cells are shown in Fig. 1. PBMCs from periodontitis subjects released higher levels of TNF- $\alpha$ (Fig. 1a) and IL-6 (Fig. 1b) than those from healthy subjects $(P<0.05)$. In contrast, supernatants of the stimulated PBMCs obtained from healthy subjects presented higher amounts of IL-8 (Fig. 1C) than those obtained from periodontitis individuals $(P<0.05)$. No differences were observed in the levels of IL-10 (Fig. 1d) between supernatants of the E. coli LPSstimulated PBMCs obtained from periodontitis and healthy subjects $(P>0.05)$.

\section{Discussion}

The present ex vivo study showed that PBMC from individuals with generalized chronic periodontitis and no history of systemic diseases released increased levels of TNF- $\alpha$ and IL- 6 (Fig. 1a and b). The overproduction of such pro-inflammatory cytokines suggests a hyper-reactivity of PBMC from periodontitis subjects that may favour periodontal tissue destruction and systemic inflammatory burden. Clinically, the levels of TNF- $\alpha$ and IL- 6 in the plasma of subjects with periodontitis remain controversial. ${ }^{23-27}$ Some studies have found higher plasma levels of TNF- $\alpha$ and IL- 6 in subjects with periodontitis than healthy controls and a reduction after periodontal therapy; whilst others have not found this association. ${ }^{23-27}$ The results of the present study from PBMC are in line with an earlier investigation that also demonstrated that LPS-stimulated monocytes from periodontitis subjects released higher levels of TNF- $\alpha$ than those from control subjects. ${ }^{28}$ In support of our data, Gustafsson et al. ${ }^{29}$ also showed a tendency for a higher release of TNF- $\alpha$ by stimulated mononuclear cells from subjects with treated periodontitis when compared to healthy ones. Conversely, our results are in contrast to studies that found no differences in the release of TNF- $\alpha$ and IL- 6 in the $E$. coli LPS-stimulated whole blood cell cultures (WBCC) from periodontitis and healthy subjects. ${ }^{19,30}$ These contradictory results could be explained by some methodological differences related to the inclusion of smokers, ethnical characteristics of the populations, sample size, types (chronic or aggressive) and severity of periodontitis, type of cell culture (WBCC or PBMC), time and methods of cell stimulation and ELISA assay.

The present study showed that the levels of IL-8 were elevated in PBMC supernatant from healthy subjects (Fig. 1c), suggesting a higher capacity for induction of chemotaxis, migration and activation of neutrophils in the non-periodontitis subjects. ${ }^{9}$ Contrary to our results, Fokkema et al. ${ }^{19}$ demonstrated that the secretion of IL- 8 in the supernatants of stimulated WBCC from periodontitis subjects were higher than those from controls. In support of the Fokkema et al. findings, ${ }^{19}$ previous investigations have also demonstrated that the plasma levels of IL-8 were higher in subjects with periodontitis than in healthy individuals. ${ }^{26,31}$ On the other hand, Restaíno et al. ${ }^{32}$ showed that IL- 8 secretion promoted by various stimulating agents in WBCC did not differ between periodontitis and control groups. Interestingly, the authors observed that, unlike the healthy group, the levels of IL-8 secreted by stimulated neutrophils from periodontitis subjects were significantly lower than those from periodontally healthy subjects. However, methodological differences amongst studies, especially in relation to the type of cell cultures (PBMC, WBCC or neutrophils), have hampered a direct comparison amongst previous investigations and our IL-8 data.

No differences were observed between periodontitis and healthy groups with regard to the levels of IL-10 (Fig. 1d), indicating that stimulated PBMC of periodontitis and nonperiodontitis subjects may present a similar ability to produce this regulatory cytokine. These findings are supported by previous studies using the supernatants of stimulated WBCC from chronic and aggressive periodontitis. ${ }^{19,20}$ In relation to the plasma levels of IL-10, Monteiro et al. ${ }^{26}$ did not find differences in the concentration of IL-10 between chronic periodontitis and healthy subjects. On the other hand, Havemose-Poulsen et al. ${ }^{20}$ observed higher plasma levels of IL-10 in generalized aggressive periodontitis individuals, when compared to healthy ones. Thus, the profile of IL-10 release by PBMC obtained from chronic and aggressive periodontitis seems to be an interesting topic that may be evaluated in further studies.

Since a link between periodontal diseases and systemic complications has been proposed, it has been increased the interest in defining the behaviour of peripheral blood cells in periodontitis subjects. Serological differences in well established risk markers for systemic diseases (e.g. CRP) and an increased level of circulating monocytes have been observed in subjects with periodontitis. ${ }^{20,33,34}$ However, to date, the exact relationship amongst periodontal diseases, systemic inflammation and cytokines remains unclear. The chronic challenge of periodontal diseases may act as a source of bacterial virulence factors and pro-inflammatory cytokines that may cause systemic inflammatory reactions. Concomitantly, both local and systemic immunological responses may differ between periodontally healthy and diseased subjects due to a number of polymorphisms of the genes coding for the synthesis of inflammatory mediators and for the reactivity of inflammatory cells. Unfortunately, the cross-section design of the present study hampers a temporal association between periodontal disease activity and the profile of cytokines released by the PBMC. Gustafsson et al. ${ }^{29}$ demonstrated that mononuclear cells and neutrophils from subjects with treated periodontitis and slight periodontal inflammation are also hyper-reactive when compared to periodontally healthy subjects. In addition, data on whether periodontal therapy affects the serum levels of CRP and other systemic markers are still inconclusive. ${ }^{23-35}$ Therefore, it is reasonable to suggest that subjects with periodontitis may have a constitutionally 
different host response in PMBCs, independent of the presence of active disease. From these findings, it may also be speculated that high reactivity of immune cells to LPS may be a susceptibility factor for both periodontal tissue breakdown and systemic diseases in individuals with periodontitis.

It is likely that the levels of the inflammatory mediators observed in the PBMC supernatants of the present study are mainly due to responses of monocytes/macrophages, which are the chief cells of innate immunity. ${ }^{36}$ Finally, it is important to emphasize that it is not possible to state whether the amounts of cytokines released by our ex vivo stimulated PBMC may reflect the levels of the cytokines in the plasma.

In conclusion, the results of the present study showed that E. coli LPS-stimulated PBMC from subjects with periodontitis present a different profile of cytokine release when compared those from healthy subjects. Since inflammatory molecules work in a network-like organization, further studies are necessary to better elucidate the pattern of the release of other mediators, as well as to assess the clinical implications of these events on the progression and severity of the periodontal diseases and systemic inflammation.

\section{Acknowledgements}

Funding: The authors thank FAPESB (Bahian Foundation for Science, Salvador, BA, Brazil, Support \#031/2005) that supported this research.

Competing interests: The authors declare that they have no conflict of interest.

Ethical approval: The Review Ethics Board of the Faculty of Dentistry of Piracicaba has approved this protocol (\#049/2005).

\section{R E F E R E N C E S}

1. Page RC, Kornman KS. The pathogenesis of human periodontitis: an introduction. Periodontol 2000 1997;14:9-11.

2. Williams RC, Offenbacher S. Periodontal medicine: the emergence of a new branch of periodontology. Periodontol 2000 2000;23:9-12.

3. Paquette DW. The periodontal infection-systemic disease link: a review of the truth or myth. J Int Acad Periodontol 2002;4(3):101-9.

4. Ogrendik M. Rheumatoid arthritis is linked to oral bacteria: etiological association. Mod Rheumatol 2009;19(5):453-6.

5. Haraszthy VI, Zambon JJ, Trevisan M, Zeid M, Genco RJ. Identification of periodontal pathogens in atheromatous plaques. J Periodontol 2000;71(10):1554-60.

6. De Nardin E. The role of inflammatory and immunological mediators in periodontitis and cardiovascular disease. Ann Periodontol 2001;6(1):30-40.

7. Beck JD, Offenbacher S. Systemic effects of periodontitis: epidemiology of periodontal disease and cardiovascular disease. J Periodontol 2005;76(11 Suppl.):2089-100.

8. Seymour GJ, Gemmell E. Cytokines in periodontal disease: where to from here? Acta Odontol Scand 2001;59(3):167-73.

9. Kobayashi Y. The role of chemokines in neutrophil biology. Front Biosci 2008;13:2400-7.

10. Wajant H, Pfeffer K, Pfizenmaier K, Scheurich P. Tumor necrosis factors in 1998. Cytokine Growth Factor Rev 1998; 9(3-4):297-302.
11. Boyce BF, Li P, Yao Z, Zhang Q, Badell IR, Schwarz EM, et al. TNF-alpha and pathologic bone resorption. Keio J Med 2005;54(3):127-31.

12. Ryan S, Taylor CT, McNicholas WT. Systemic inflammation: a key factor in the pathogenesis of cardiovascular complications in obstructive sleep apnoea syndrome? Thorax 2009;64(7):631-6.

13. Abeywardena MY, Leifert WR, Warnes KE, Varghese JN, Head RJ. Cardiovascular biology of interleukin-6. Curr Pharm Des 2009;15(15):1809-21.

14. Maynard CL, Weaver CT. Diversity in the contribution of interleukin-10 to T-cell-mediated immune regulation. Immunol Rev 2008;226:219-33.

15. Barth S, Kleinhappl B, Gutschi A, Jelovcan S, Marth E. In vitro cytokine mRNA expression in normal human peripheral blood mononuclear cells. Inflamm Res 2000;49(6):266-74.

16. Bomprezzi R, Ringnér M, Kim S, Bittner ML, Khan J, Chen Y, et al. Gene expression profile in multiple sclerosis patients and healthy controls: identifying pathways relevant to disease. Hum Mol Genet 2003;12(17):2191-9.

17. Sørensen LK, Havemose-Poulsen A, Bendtzen K, Holmstrup P. Aggressive periodontitis and chronic arthritis: blood mononuclear cell gene expression and plasma protein levels of cytokines and cytokine inhibitors. J Periodontol 2009;80(2):282-9.

18. Petit MD, Wassenaar A, van der Velden U, van Eden W, Loos BG. Depressed responsiveness of peripheral blood mononuclear cells to heat-shock proteins in periodontitis patients. J Dent Res 1999;78(8):1393-400.

19. Fokkema SJ, Loos BG, Slegte C, van der Velden U. A type 2 response in lipopolysaccharide (LPS)-stimulated whole blood cell cultures from periodontitis patients. Clin Exp Immunol 2002;127(2):374-8.

20. Havemose-Poulsen A, Sørensen LK, Stoltze K, Bendtzen K, Holmstrup P. Cytokine profiles in peripheral blood and whole blood cell cultures associated with aggressive periodontitis, juvenile idiopathic arthritis, and rheumatoid arthritis. J Periodontol 2005;76(12):2276-85.

21. Yamaguchi R, Yoshimura A, Yoshioka H, Kaneko T, Hara Y. Ability of supragingival plaque to induce toll-like receptor 4mediated stimulation is associated with cytokine production by peripheral blood mononuclear cells. $J$ Periodontol 2009;80(3):512-20.

22. Armitage GC. Development of a classification system for periodontal diseases and conditions. Ann Periodontol 1999;4(1):1-6.

23. Ide M, McPartlin D, Coward PY, Crook M, Lumb P, Wilson RF. Effect of treatment of chronic periodontitis on levels of serum markers of acute-phase inflammatory and vascular responses. J Clin Periodontol 2003;30(4):334-40.

24. D'Aiuto F, Parkar M, Andreou G, Suvan J, Brett PM, Ready D, et al. Periodontitis and systemic inflammation: control of the local infection is associated with a reduction in serum inflammatory markers. J Dent Res 2004;83(2):156-60.

25. Yun F, Firkova EI, Xun H, Jun-Qi L. Effects of surgical periodontal therapy on serum levels of TNF-alpha in patients with chronic periodontitis. Folia Med (Ploudiv) 2007;49(1-2):37-40.

26. Monteiro AM, Jardini MA, Alves S, Giampaoli V, Aubin EC, Figueiredo Neto AM, et al. Cardiovascular disease parameters in periodontitis. J Periodontol 2009;80(3):378-88.

27. Marcaccini AM, Meschiari CA, Sorgi CA, Saraiva MC, de Souza AM, Faccioli LH, et al. Circulating interleukin- 6 and high-sensitivity C-reactive protein decrease after periodontal therapy in otherwise healthy subjects. $J$ Periodontol 2009;80(4):594-602.

28. McFarlane CG, Reynolds JJ, Meikle MC. The release of interleukin-1 beta, tumor necrosis factor-alpha and interferon-gamma by cultured peripheral blood 
mononuclear cells from patients with periodontitis. $J$ Periodontal Res 1990;25(4):207-14.

29. Gustafsson A, Ito H, Asman B, Bergström K. Hyper-reactive mononuclear cells and neutrophils in chronic periodontitis. J Clin Periodontol 2006;33(2):126-9.

30. Shapira L, Soskolne WA, Sela MN, Offenbacher S, Barak V. The secretion of PGE2, IL-1 beta, IL-6, and TNF alpha by adherent mononuclear cells from early onset periodontitis patients. J Periodontol 1994;65(2):139-46.

31. Gainet J, Chollet-Martin S, Brion M, Hakim J, GougerotPocidalo MA, Elbim C. Interleukin-8 production by polymorphonuclear neutrophils in patients with rapidly progressive periodontitis: an amplifying loop of polymorphonuclear neutrophil activation. Lab Invest 1998;78(6):755-62.

32. Restaíno CG, Chaparro A, Valenzuela MA, Kettlun AM, Vernal R, Silva A. Stimulatory response of neutrophils from periodontitis patients with periodontal pathogens. Oral Dis 2007;13(5):474-81.

33. Buhlin K, Gustafsson A, Pockley AG, Frostegård J, Klinge B. Risk factors for cardiovascular disease in patients with periodontitis. Eur Heart J 2003;24(23):2099-107.

34. Johansson A, Buhlin K, Koski R, Gustafsson A. The immunoreactivity of systemic antibodies to Actinobacillus actinomycetemcomitans and Porphyromonas gingivalis in adult periodontitis. Eur J Oral Sci 2005;113(3):197-202.

35. Mattila K, Vesanen M, Valtonen V, Nieminen M, Palosuo T, Rasi V, et al. Effect of treating periodontitis on C-reactive protein levels: a pilot study. BMC Infect Dis 2002;2:30.

36. Cavaillon JM, Marie C, Pitton C, Fitting C. The production of TNF alpha and IL-8 in whole blood assays are differently regulated upon activation by LPS. Prog Clin Biol Res 1995;392:433-9. 